\title{
Spirometric indices in primary ciliary dyskinesia: systematic review and meta-analysis
}

\author{
Florian S. Halbeisen (10 ${ }^{1}$, Anu Jose ${ }^{1}$, Carmen de Jong ${ }^{1}$, Sylvia Nyilas ${ }^{2,3}$, \\ Philipp Latzin (10 ${ }^{2}$, Claudia E. Kuehni (10,2 and Myrofora Goutaki (i] ${ }^{1,2}$
}

Affiliations: ${ }^{1}$ Institute of Social and Preventive Medicine, University of Bern, Bern, Switzerland. ${ }^{2}$ Paediatric Respiratory Medicine, Children's University Hospital of Bern, University of Bern, Bern, Switzerland. ${ }^{3}$ Dept of Diagnostic, Interventional and Pediatric Radiology, Inselspital, University of Bern, Bern, Switzerland.

Correspondence: Myrofora Goutaki, Institute of Social and Preventive Medicine, University of Bern, Finkenhubelweg 11, 3012 Bern, Switzerland. E-mail: myrofora.goutakidispm.unibe.ch

ABSTRACT Primary ciliary dyskinesia (PCD) is a genetic, heterogeneous disease caused by dysfunction of cilia. Evidence is sparse and reports of lung function in PCD patients range from normal to severe impairment. This systematic review and meta-analysis of studies of lung function in PCD patients examines the spirometric indices of PCD patients and differences by age group and sex.

We searched PubMed, Embase and Scopus for studies that described lung function in 10 or more patients with PCD. We performed meta-analyses and meta-regression to explain heterogeneity. We included 24 studies, ranging from 13 to 158 patients per study.

The most commonly reported spirometric indices were forced expiratory volume in $1 \mathrm{~s}$ (FEV1) and forced vital capacity presented as mean and standard deviation of percent predicted values. We found considerable heterogeneity for both parameters $\left(I^{2}=94-96 \%\right)$. The heterogeneity remained when we stratified the analysis by age; however, FEV1 in adult patients was lower. Even after taking into account explanatory factors, the largest part of the between-studies variance remained unexplained.

Heterogeneity could be explained by genetic differences between study populations, methodological factors related to the variability of study inclusion criteria or details on the performance and evaluation of lung function measurements that we could not account for. Prospective studies therefore need to use standardised protocols and international reference values. These results underline the possibility of distinct PCD phenotypes as in other chronic respiratory diseases. Detailed characterisation of these phenotypes and related genotypes is needed in order to better understand the natural history of PCD.

@ERSpublications

Spirometric indices of PCD patients vary between published studies, which suggests not only the possibility of methodological differences between centres but also real differences in disease expression based on genotype-phenotype associations http://ow.ly/wopw30nYaJo

Cite this article as: Halbeisen FS, Jose A, de Jong C, et al. Spirometric indices in primary ciliary dyskinesia: systematic review and meta-analysis. ERJ Open Res 2019; 5: 00231-2018 [https://doi.org/ 10.1183/23120541.00231-2018].

This article has supplementary material available from openres.ersjournals.com.

Received: Dec 032018 | Accepted after revision: Feb 282019

Copyright $\odot$ ERS 2019. This article is open access and distributed under the terms of the Creative Commons Attribution Non-Commercial Licence 4.0. 


\section{Introduction}

Primary ciliary dyskinesia (PCD) is a genetic, heterogeneous disease caused by absence and/or dysfunction of cilia [1]. Its prevalence is estimated to be around 1 in 10000 , but it is underdiagnosed [2]. It can affect ciliated cells throughout the body and lead to numerous manifestations, primarily in the respiratory system [3]. Most patients suffer from chronic and recurrent upper respiratory infections from early in life, which can lead to lung damage and bronchiectasis as the disease progresses [1, 4].

Lung function is one of the most important predictors of overall survival among both healthy individuals and patients with chronic lung disease [5]. Spirometry, which is widely available, is the easiest and most common method of testing pulmonary function. Spirometric indices, primarily forced expiratory volume in $1 \mathrm{~s}$ (FEV1), are used to monitor progression and describe severity in chronic respiratory diseases such as cystic fibrosis or chronic obstructive pulmonary disease [6-8]. In PCD patients, several studies have reported results of lung function measurements; however, their findings are contradictory, ranging from normal lung function to significant impairment. Most studies have focused on paediatric or young adult patients and reports from older patients are rare. Data on sex differences are also scarce, although evidence is growing that a number of pulmonary diseases affect females and males differently [9]. A detailed overview and comparison of existing studies of lung function is necessary to inform PCD research about existing and improved use of spirometry, and to determine where more evidence is needed in the study and treatment of PCD.

This systematic review and meta-analysis therefore identifies all published studies presenting lung function in patients with PCD, and it summarises spirometric indices reported in those studies. We also identify differences in these spirometric indices between male and female patients and between paediatric and adult patients.

\section{Methods}

The protocol we developed for the systematic review is summarised here. We followed the PRISMA guidelines for reporting [10].

\section{Search strategy}

We searched PubMed, Embase and Scopus with no restriction of language or study design for studies published between January 1980 and February 2017 that described lung function in patients with PCD (Orphanet classification ORPHA:244).

We tested multiple search terms to decide on the most appropriate term for each database. We selected the most concise terms that identified the largest number of studies.

PubMed: (("kartagener syndrome”[Title/Abstract] OR "primary ciliary dyskinesia”[Title/Abstract] OR "ciliary motility disorders" [MeSH Terms]) AND ("lung function" OR "respiratory function" OR "pulmonary function" OR "lung volume" OR "forced vital capacity" OR "forced expiratory volume" OR "FEV" OR "FEV1" OR "spirometry" OR “wash out” OR "Follow-Up Studies" [MeSH] OR "Respiratory Function Tests" [MeSH])).

Embase: “primary ciliary dyskinesia”:ab,ti OR "kartagener”:ab,ti OR "kartageners":ab,ti OR “ciliary motility disorder":ab,ti AND ("lung function" OR "respiratory function" OR "pulmonary function" OR "lung volume" OR "spirometry" OR "fev" OR "forced expiratory volume" OR "forced vital capacity" OR "fev1" OR "plethysmography” OR “wash out”).

Scopus: ((TITLE-ABS-KEY(“primary ciliary dyskinesia”)) OR (TITLE-ABS-KEY("kartagener”)) OR (TITLE-ABS-KEY(“ciliary motility disorder”))) AND ((“wash out”) OR ((“lung function”) OR ("lung volume") OR ("respiratory function”) OR ("pulmonary function”) OR ("forced vital capacity” OR fvc) OR (“forced expiratory volume”) OR (“spirometry”))).

After identifying all eligible studies, we checked for additional citations in their reference lists. We used Endnote X5 (Thomson Reuters, Philadelphia, PA, USA) citation manager.

\section{Definition of PCD patients}

The diagnosis of PCD has changed over the period from 1980 to present $[11,12]$. The studies we included have a wide range of patient inclusion criteria, ranging from patients with a clinical diagnosis (in most cases Kartagener syndrome) to those with positive results from tests that have varied with diagnostic consensus at the time of each study: electron microscopy, light or high-speed video-microscopy, nasal nitric oxide (nNO) and genetic testing.

\section{Study selection}

We included studies reporting lung function of patients with PCD that had a study population of 10 or more patients. We excluded animal studies and those that were not original, studies that described 
diagnostic test results or genetics, but lacked information on lung function, and those that reported on other rare ciliary syndromes, such as Joubert syndrome.

We initially screened publication titles and abstracts. From our experience with PCD literature [3], we realised that many studies of PCD patients report lung function measurements without explicitly articulating this in the title or abstract. Thus, we also screened the full text of original clinical studies of PCD patients even if lung function was not mentioned in the title or abstract. After reading the full text of all potentially eligible studies, the final decision on inclusion was made by two independent reviewers, one with extensive experience in systematic reviews and knowledge of the disease. In case of disagreement, a consensus decision was reached after discussion. During the final step of inclusion, we excluded studies that did not report any spirometric indices and conference abstracts that lacked full text.

\section{Overlapping study population}

To avoid including the same patients multiple times in our review, we identified all studies that appeared to share the same study population. We compared the author list, country of origin and department where the study took place. In case we noticed a considerable overlap in the study population between two or more studies, we always included in the quantitative synthesis the study that was published most recently and included information on a larger number of patients. When two studies were published $\geqslant 10$ years apart, we included both since we believed there would be little chance of significant overlap. Where the extent of possible overlap was not clear, we contacted the study investigators for clarification.

\section{Data extraction}

We used Epidata version 3.1 (www.epidata.dk) to extract information from all studies, including those with overlapping populations. We extracted 1) author- and publication-specific information, which included author names, journal and year of publication, country, and centre of corresponding author; 2) study characteristics, which included years the study was carried out, study design, inclusion and exclusion criteria, study population size, country where the study took place, type of clinic, age of participants, and age stratification of reported lung function measurements; and 3) information on spirometry of PCD patients. For spirometry, we extracted all information reported on lung function measurements, including values of spirometric indices and information on equipment used for spirometry, quality control measures and reference values.

\section{Meta-analysis}

We performed meta-analyses of FEV1 and forced vital capacity (FVC), the most commonly reported spirometry indices, using a DerSimonian-Laird random effects model [13, 14], and assessed the heterogeneity $\left(I^{2}\right)$ between studies [15]. We assessed possible differences in lung function between children and adults by performing separate subgroup meta-analyses in adults and children. Studies that did not report FEV1 and FVC separately for adults and children or in which information on age was not available were excluded from this subgroup analysis.

We then investigated reasons for heterogeneity by fitting meta-regression models. We considered the following explanatory factors one at a time: period of publication (before 1997, 1997-2007, after 2007), number of patients included in the study $(<20,21-50,51-100,>100$ patients), retrospective or prospective study design, reference values used for spirometry (references using $\geqslant 5000$ subjects, $<5000$ subjects, no information) [16], pulmonary function test quality control (based on European Respiratory Society (ERS)/ American Thoracic Society (ATS) guidelines, used the best out of three valid measurements, no information available) and whether spirometry was the main study outcome (no, yes) [17].

Statistical analysis was performed with $\mathrm{R}$ version 3.1.2 (www.r-project.org) using the package meta version 4.3-2, specifically the commands metagen and metareg.

\section{Results}

\section{Search}

After excluding duplicates appearing in more than one of the databases (PubMed, Embase and Scopus), our initial search produced 664 articles (figure 1). We screened the titles and abstracts of these, and excluded 501 articles. Among the remaining 163 studies, 37 were either conference abstracts only or it was not possible to find the full text. After reading the full text of the remaining 126 studies, we excluded another 102 articles (figure 1), including 34 that had overlapping study populations [18-50]. Finally, we included 24 studies reporting spirometric indices of PCD patients in the meta-analysis. 


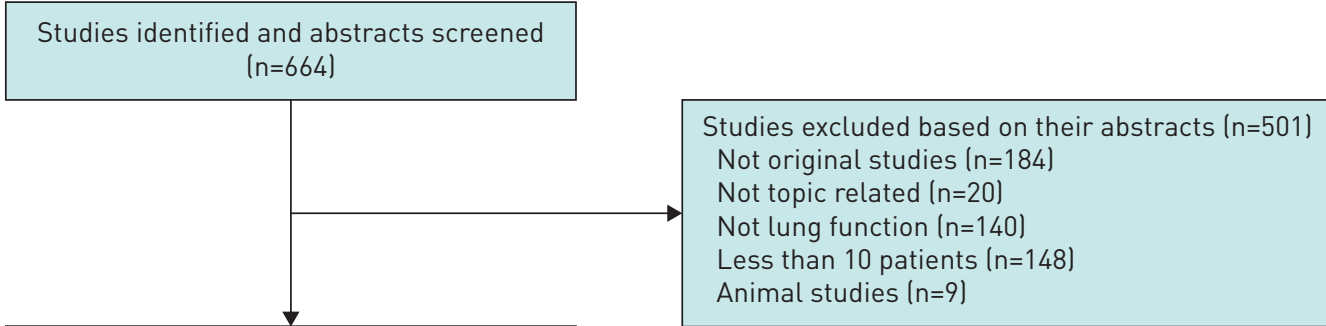

Full-text articles assessed for eligibility $(n=163)$

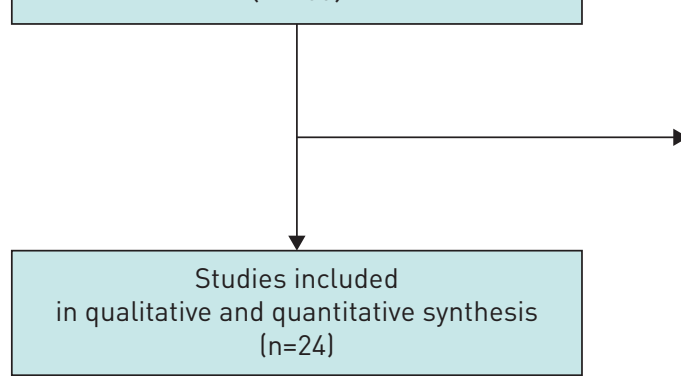

No full text available $(n=37)$

Full-text articles excluded $(\mathrm{n}=68)$

Not original studies $(n=31)$

Not topic related $(n=9)$

Not lung function/spirometry $(n=19)$

Less than 10 patients $(n=9)$

Overlapping study population $(n=34)$

FIGURE 1 Flowchart describing the selection procedure.

Study characteristics and information on spirometry

Table 1 lists the 24 studies and their characteristics [4, 51-73]. The articles encompassed a total of 1179 patients with a mean (range) number of 49 (13-158) patients per study. Most studies were relatively small, with 18 of the 24 including less than 50 patients (table 2). Nearly all studies originated from paediatric or adult pulmonology departments, or from specialised PCD centres. 17 were single-centre studies. 15 were published in the last 10 years (after 2007). 15 came from Europe, six from Asia and three were from North or South America. Seven studies included only children (age $<18$ years), three only adults (age $\geqslant 18$ years) and 14 studies had populations of mixed age consisting mainly of children with a few adults.

PCD diagnosis was established in different ways. 19 studies assessed ciliary ultrastructure using electron microscopy and/or a combination of one or more of nNO, video-microscopy and genetics according to available consensus at the time of each publication (table 2). In three of the 24 studies, the majority of patients were similarly diagnosed on the basis of ciliary ultrastructure, although a small proportion of the patients were diagnosed based only on strong clinical suspicion, mainly Kartagener syndrome. In two, older studies, all patients were diagnosed based on strong clinical suspicion, again primarily Kartagener syndrome.

All studies reported FEV1 measurements and half of them also reported FVC measurements. How investigators reported lung function measurements varied. The most commonly reported spirometric indices were FEV1 and FVC, presented as mean and standard deviation of percent predicted values. In studies in which FEV1 and FVC were reported differently or important information was not reported, we contacted the investigators for additional data. Among the 14 studies that included both paediatric and adult patients, only six of the 14 reported lung function results stratified by age groups. Only four of the 24 studies reported FEV1 and FVC as Z-scores. Eight also reported other lung function measurements such as plethysmography and multiple-breathe washout techniques or exhaled breath analysis techniques. Investigators used a variety of different spirometry reference values depending on the year of publication; 10 out of the 24 studies did not report which references were used for the calculation of the percent predicted values. 12 of the studies reported that spirometry was performed based on the ERS/ATS guidelines, while in five more the best of three acceptable spirometry measurements was chosen. The remaining seven studies did not report on quality measures of spirometry. Only seven of the 24 studies included longitudinal measurements of lung function.

Supplementary table S1 presents the characteristics of all included studies and studies with overlapping populations.

\section{Forced expiratory volume in $1 \mathrm{~s}$}

Reported FEV1 values varied significantly between the studies and mean FEV1 \% pred ranged from $51 \%$ to $96 \%$. Weighted mean FEV1 \% pred in the 24 studies was 75\% (95\% CI 69-80\%) with a heterogeneity of $I^{2}=96 \%$ (figure 2). Results remained the same when we excluded from the meta-analysis the two studies 
TABLE 1 Detailed characteristics of included studies describing spirometric indices of primary ciliary dyskinesia patients, stratified by age group of patients

\begin{tabular}{|c|c|c|c|c|c|c|c|c|c|c|c|}
\hline First author [ref.] & Country & $\begin{array}{c}\text { Year of } \\
\text { publication }\end{array}$ & $\begin{array}{c}\text { Patients } \\
\mathrm{n}\end{array}$ & Age years & $\begin{array}{l}\text { Type of } \\
\text { study }\end{array}$ & $\begin{array}{l}\text { Study } \\
\text { design }\end{array}$ & Diagnostics & $\begin{array}{l}\text { Symptoms } \\
\text { stratified by } \\
\text { age }\end{array}$ & $\begin{array}{l}\text { Longitudinal } \\
\text { data }\end{array}$ & FEV & FVC \\
\hline \multicolumn{12}{|l|}{ Children } \\
\hline AL SAADI [51] & Saudi Arabia & 2013 & 22 & $10.86 \pm 3.09^{\#}$ & Prospective & Case-control & $\mathrm{EM}+\mathrm{HFVM}$ & NA & - & + & - \\
\hline Davis [55] & USA/Canada & 2015 & 118 & $8(5-11)^{\uparrow}$ & Prospective & Case series & $\begin{array}{c}\text { EM or genetic } \\
\text { analysis }\end{array}$ & NA & - & + & - \\
\hline GoKDEMIR [58] & Turkey & 2014 & 24 & $12.9 \pm 2.7^{\#}$ & Prospective & Clinical trial & EM or Kartagener & NA & - & + & + \\
\hline KARADAG [61] & UK & 1999 & 21 & $10.8 \pm 3.2^{\#}$ & Retrospective & Case-control & $E M, H F V M$ & NA & - & + & + \\
\hline Кон [62] & Korea & 2000 & 19 & $12(7-16)^{+}$ & Prospective & Clinical trial & EM & NA & - & + & - \\
\hline MAGLIONE [63] & $\begin{array}{c}\text { Denmark, Italy and } \\
\text { UK }\end{array}$ & 2014 & 158 & $8.7(4.2-17.4)^{\S}$ & Retrospective & Cohort & $\begin{array}{l}\text { According to } \\
\text { consensus }\end{array}$ & NA & + & + & + \\
\hline PAFF $[68]$ & The Netherlands & 2013 & 25 & $10.7(7.1-14.5)^{9}$ & Prospective & Case-control & $\begin{array}{l}\text { According to } \\
\text { consensus }\end{array}$ & NA & - & + & - \\
\hline \multicolumn{12}{|l|}{ Adults } \\
\hline FRIJA-MASSON [57] & France & 2017 & 78 & $34.8(28.6-47.1)^{\pi}$ & Retrospective & Case series & $\begin{array}{l}\text { EM, genetic } \\
\text { analysis or } \\
\text { Kartagener }\end{array}$ & NA & + & + & + \\
\hline HoRVATH [60] & UK & 2003 & 14 & $35 \pm 4.6^{\#}$ & Prospective & Case-control & EM, HFVM & NA & - & + & + \\
\hline Mossberg [65] & Sweden & 1983 & 24 & $30(19-47)^{\S}$ & Prospective & Case series & Clinical suspicion & NA & - & + & - \\
\hline \multicolumn{12}{|l|}{$\begin{array}{l}\text { Both children } \\
\text { and adults }\end{array}$} \\
\hline AMIRAV [52] & Israel & 2016 & 13 & $10(5-43)^{\pi}$ & Retrospective & Case series & $\begin{array}{l}\text { All tests, including } \\
\text { genetic analysis }\end{array}$ & - & - & + & - \\
\hline Boon [53] & Belgium & 2014 & 122 & $17.7(9.5-28.1)^{\pi}$ & Retrospective & Case series & $\begin{array}{c}\text { EM, HFVM, genetic } \\
\text { analysis }\end{array}$ & - & - & + & + \\
\hline COHEN-CYMBERKNoH [54] & Israel & 2014 & 14 & $15.9 \pm 8.6^{\#}$ & Retrospective & Case series & $\begin{array}{l}\text { EM, HFVM, nNO, } \\
\text { genetic analysis }\end{array}$ & - & - & + & - \\
\hline ELLERMAN [56] & Denmark & 1997 & 24 & $21 \pm 13.6^{\#}$ & Prospective & Case series & HFVM & + & + & + & + \\
\hline HELLINCKX [59] & Belgium & 1998 & 11 & $15.2 \pm 7^{\#}$ & Prospective & Case series & EM, HFVM & + & + & + & - \\
\hline MAHUT [64] & France & 2006 & 16 & $13.5(12-17)^{\text {I1 }}$ & Retrospective & Case series & Clinical, EM & + & - & + & - \\
\hline NoOne [4] & USA and Canada & 2004 & 78 & $\begin{array}{l}\text { Adults: } 36(19-73)^{+} \text {; } \\
\text { children: } 8(1-17)^{+}\end{array}$ & Prospective & Case series & $\begin{array}{c}\text { EM, HFVM, genetic } \\
\text { analysis }\end{array}$ & + & - & + & - \\
\hline NYILAS [66] & $\begin{array}{l}\text { Germany and } \\
\text { Switzerland }\end{array}$ & 2017 & 49 & $14.7 \pm 6.6^{\#}$ & Prospective & Case-control & All tests & - & - & + & + \\
\hline OLM [67] & Brazil & 2011 & 10 & $13.4 \pm 4.7^{\#}$ & Prospective & Case-control & $\mathrm{EM}+\mathrm{HFVM}$ & + & - & + & + \\
\hline PIFFERI [69] & Italy & 2015 & 45 & $14(22.25)^{\pi}$ & Prospective & Case-control & EM, HFVM, nNO & - & - & + & + \\
\hline SHAH [70] & UK & 2016 & 118 & $23.5(10-36)^{\pi}$ & Retrospective & Case series & $\begin{array}{l}\text { EM, HFVM, nNO, } \\
2 \% \text { clinical }\end{array}$ & - & + & + & - \\
\hline ToLUSAKow [71] & Germany & 1981 & 21 & $3-43^{f}$ & Retrospective & Case series & Clinical suspicion & - & - & + & + \\
\hline VALLET [72] & France & 2013 & 41 & $6(3-11)^{9}$ & Retrospective & Case series & EM, HFVM & - & + & + & + \\
\hline YIALLOUROS [73] & Cyprus & 2015 & 20 & $0.1-58.4^{f}$ & Retrospective & Case series & $\mathrm{EM}$ or $\mathrm{HFVM}+\mathrm{nNO}$ & + & + & + & + \\
\hline
\end{tabular}

FEV1: forced expiratory volume in $1 \mathrm{~s}$; FVC: forced vital capacity; EM: electron microscopy; HFVM: high-frequency video-microscopy; NA: not applicable; nNO: nasal nitric oxide. Age is reported in different formats depending on the available information: ${ }^{\#}:$ mean $\pm \mathrm{SD} ;{ }^{\uparrow}:$ median (interquartile range); ${ }^{+}:$median (range); ${ }^{8}:$ mean (range); ${ }^{f}:$ range. 


\begin{tabular}{|c|c|}
\hline Total studies & $24(100)$ \\
\hline \multicolumn{2}{|l|}{ Study size } \\
\hline$\leqslant 20$ patients & 8 (33) \\
\hline $21-50$ patients & $10(42)$ \\
\hline $51-100$ patients & $2(8)$ \\
\hline$>100$ patients & $4(17)$ \\
\hline \multicolumn{2}{|l|}{ Number of centres } \\
\hline Single centre & $17(71)$ \\
\hline Multicentre & $7(29)$ \\
\hline \multicolumn{2}{|l|}{ Publication period } \\
\hline$\leqslant 1996$ & $2(8)$ \\
\hline $1997-2007$ & $7(29)$ \\
\hline$\geqslant 2008$ & $15(63)$ \\
\hline \multicolumn{2}{|l|}{ Study region } \\
\hline Europe & $15(62.5)$ \\
\hline Asia & $6(25)$ \\
\hline North and South America & $3(12.5)$ \\
\hline \multicolumn{2}{|l|}{ Age of participants } \\
\hline Children $<18$ years & 7 (29) \\
\hline Adults $\geqslant 18$ years & $3(13)$ \\
\hline Children and adults & $14(58)$ \\
\hline \multicolumn{2}{|l|}{ Study design } \\
\hline Retrospective & $11(46)$ \\
\hline Prospective & $13(54)$ \\
\hline \multicolumn{2}{|l|}{ Diagnostics performed } \\
\hline Diagnosis based only on strong clinical suspicion & $2(8)$ \\
\hline $\begin{array}{l}\text { Diagnosis based on EM or a combination of tests in most patients; } \\
\text { few only on strong clinical suspicion }\end{array}$ & 3 (13) \\
\hline Diagnosis based on EM or a combination of tests in all patients $\#$ & 19 (79) \\
\hline \multicolumn{2}{|l|}{ Spirometry indices reported } \\
\hline FEV1 & $24(100)$ \\
\hline FVC & $12(50)$ \\
\hline Information for different age groups & $6(43)^{\pi}$ \\
\hline Longitudinal information & $8(33)$ \\
\hline
\end{tabular}

Data are presented as $\mathrm{n}(\%)$. EM: electron microscopy; FEV1: forced expiratory volume in $1 \mathrm{~s}$; FVC: forced vital capacity. ${ }^{\#}$ : combination of the following: EM, nasal nitric oxide, high-frequency video-microscopy or light microscopy, or genetic analysis. "?: of 14 studies including children and adults.

having only clinically diagnosed patients. In the subgroup meta-analyses, including the 16 studies with information on age groups, eight studies reported $\mathrm{FEV}_{1}$ measurements in patients aged $\geqslant 18$ years and 13 reported FEV 1 measurements in children aged $<18$ years. In adults, mean $\mathrm{FEV}_{1} \%$ pred values ranged from $44 \%$ to $79 \%$ with a weighted mean value of $63 \%$ (95\% CI $57-69 \%$ ) and $I^{2}=91 \%$ (figure 3 ). In children, mean FEV1 \% pred values ranged from $73 \%$ to $96 \%$ with a weighted mean value of $81 \%$ (95\% CI $78-83 \%$ ) and $I^{2}=78 \%$ (figure 3 ).

\section{Forced vital capacity}

In the 13 studies including FVC \% pred results, reported values ranged from $66 \%$ to $92 \%$. Weighted mean FVC $\%$ pred was $83 \%$ (95\% CI $78-89 \%$ ) with a heterogeneity of $I^{2}=94 \%$ (figure 4 ). In the subgroup meta-analyses, we included four studies reporting FVC measurements for patients aged $\geqslant 18$ years and six studies of children aged $<18$ years. In adults, mean FVC \% pred values ranged from $70 \%$ to $94 \%$ with a weighted mean value of $79 \%$ (95\% CI $70-88 \%$ ) and $I^{2}=89 \%$ (supplementary figure S1). In children, mean FVC $\%$ pred values ranged from $77 \%$ to $90 \%$ with a weighted mean value of $85 \%$ (95\% CI $80-90 \%$ ) and $I^{2}=72 \%$ (supplementary figure $\mathrm{S} 1$ ).

\section{Meta-regression}

Meta-regressions showed that the explanatory factors explained only a small part of the between-studies variance for all symptoms. Studies published after 2007 reported higher mean values of FEV1 and FVC (both $\mathrm{p}=0.01$ ). Another factor that explained part of the heterogeneity was the reference values for 


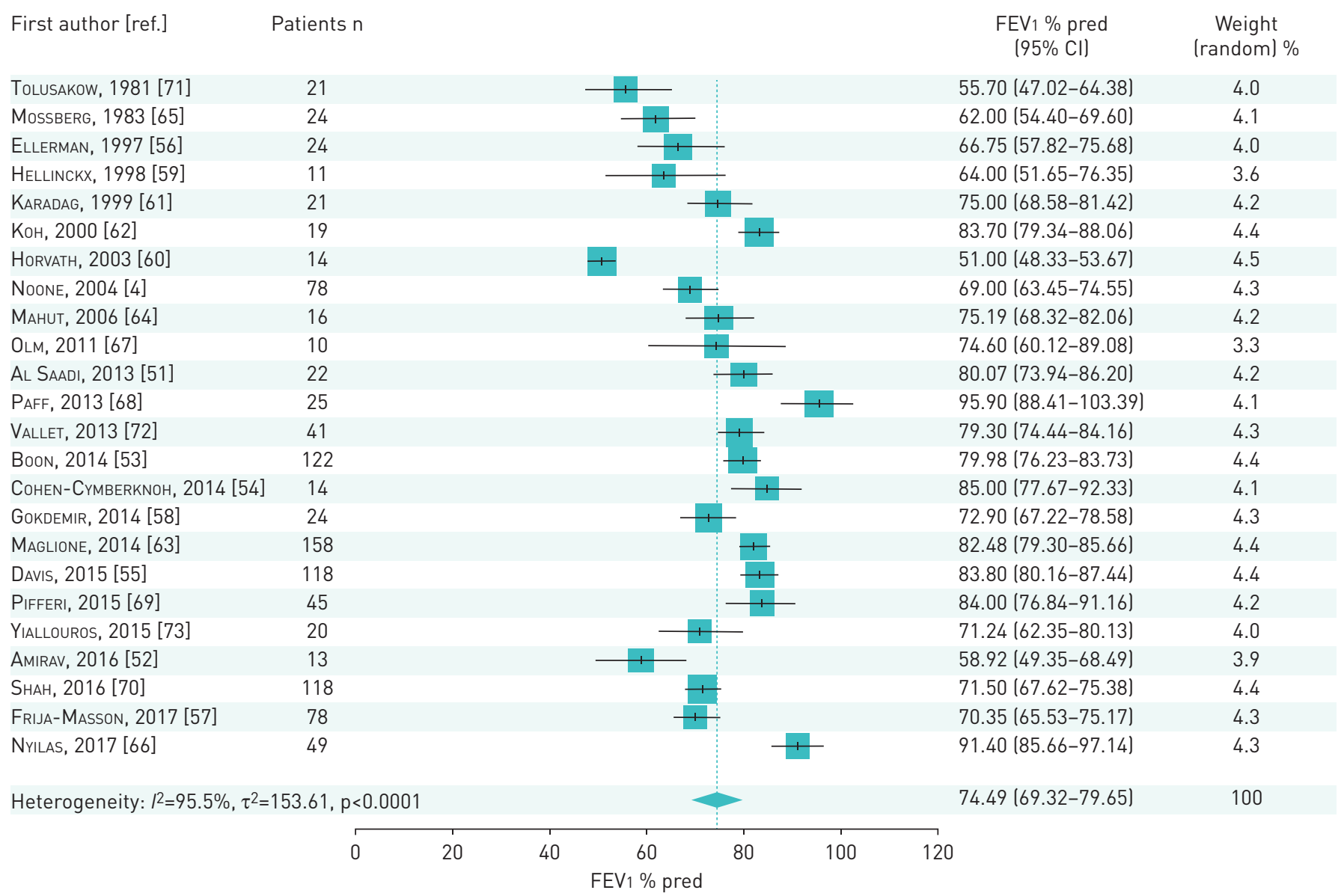

FIGURE 2 Forced expiratory volume in $1 \mathrm{~s}\left(\mathrm{FEV}_{1}\right)$ in primary ciliary dyskinesia patients: forest plot showing the heterogeneity and weighted mean value of $\mathrm{FEV} 1 \%$ pred in the included studies.

spirometry. Studies that did not report the reference values they used reported lower mean values for both FEV 1 and FVC ( $p=0.003$ and $p=0.002$, respectively). Mean FEV 1 was lower in studies that did not include any information on pulmonary function test quality control $(\mathrm{p}=0.02)$. Detailed results of the meta-regression models are presented in supplementary table S2.

\section{Differences between males and females}

Only two of the 24 studies compared lung function of male and female patients. In a large cohort of French adult patients, the spirometric indices of females were lower than those of males at the end of the study and the annual decline of FEV1 was also greater in females [57]. In contrast, no difference by sex was reported in a large British adult cohort [70].

\section{Longitudinal data}

Finally, although a preponderance of PCD studies made cross-sectional assessments, seven of the 24 studies in our meta-analysis followed lung function of PCD patients longitudinally, as did a further five of the 34 studies in which we observed overlapping populations. The differing designs and follow-up times of these 12 longitudinal studies disallow pooling their results in a meta-analysis. However, we offer a qualitative overview of the findings reported in them.

Four studies reported that most patients had stable spirometric indices (FEV1 and FVC) during respective short-term or longer follow-ups [56, 59, 63, 72]. Four other more recent studies including adult patients reported important declines of FEV1 and/or FVC [27, 40, 57, 70]. A study of the Danish national cohort of PCD patients [25] reported at least a $10 \%$ decrease in FEV1 \% pred in one-third of the patients, although great variation in lung function was observed after follow-up. In the British adult cohort, an ultrastructural defect was associated with lung function decline: patients with a microtubular defect reported a steeper decline [70], a finding that was not consistent with the results of a study of 60 French children with PCD [72]. Larger national or multicentre studies reported no association between lung 


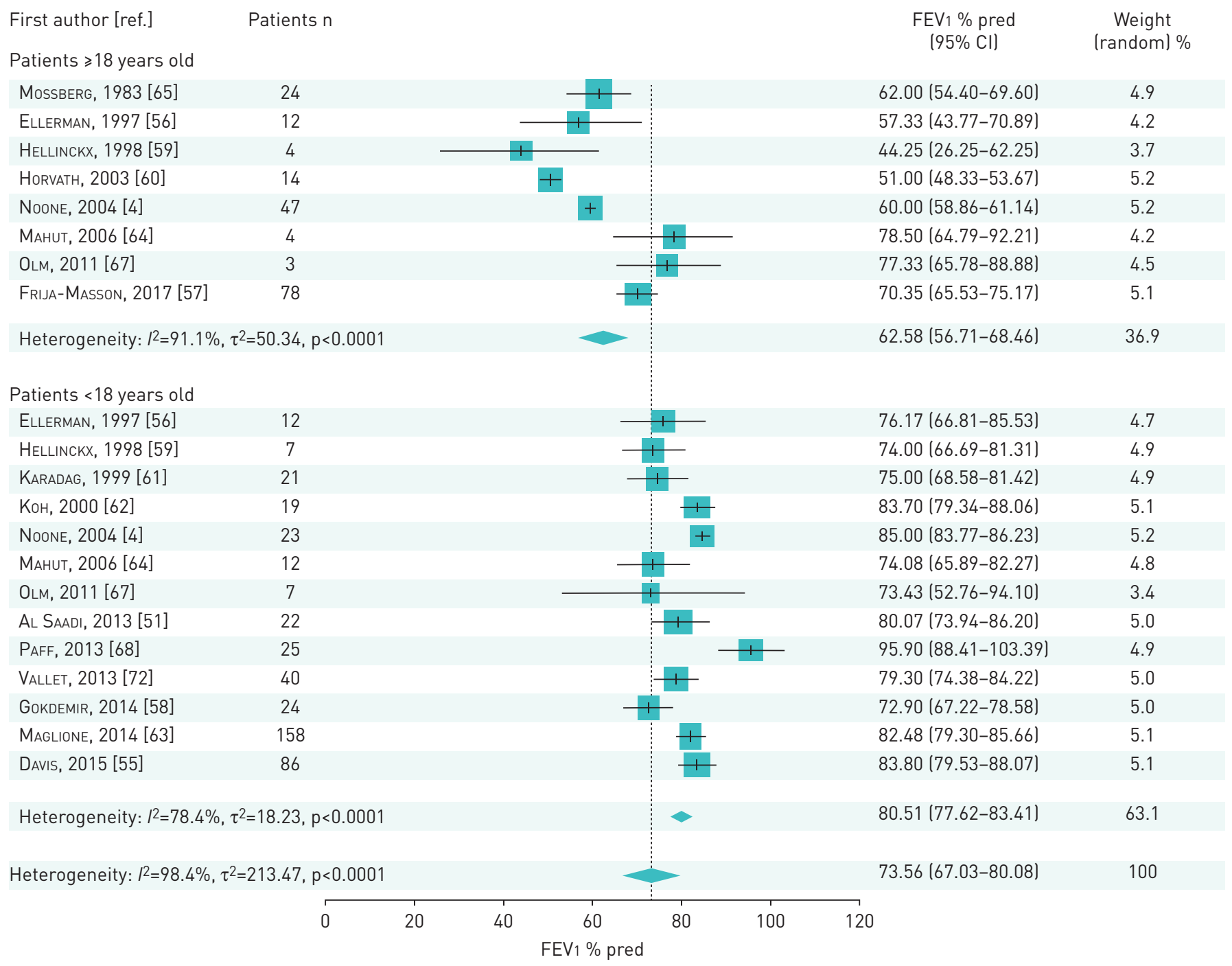

FIGURE 3 Forced expiratory volume in $1 \mathrm{~s}\left(\mathrm{FEV}_{1}\right)$ in primary ciliary dyskinesia patients by age group: forest plot showing the heterogeneity and weighted mean value of $\mathrm{FEV}_{1} \%$ pred in the included studies.

function decline and age of diagnosis [25, 63]. Preliminary results from 71 patients included in the international PCD registry showed an annual mean decline of $0.59 \%$ in $\mathrm{FEV} 1 \%$ pred and of $0.39 \%$ in FVC \% pred [40]. Recent, smaller studies have evaluated the effect of managing lung function of PCD patients with, for example, lobectomy [73] and endoscopic sinus surgery [18], without observing significant differences in lung function decline.

\section{Discussion}

This is the first systematic review of lung function measurements of PCD patients. FEV1 was lower in adults than children, but studies report a wide range of FEV1 and FVC values. This heterogeneity is not accounted for by available explanatory factors. Of the 664 studies originally identified, only $9 \%$ reported spirometry of PCD patients; 34 of the studies had overlapping study populations. Most studies were small, with a mean of 49 patients per study, and less than half of the studies that included both children and adults reported lung function stratified by age. Only two studies examined differences by sex. Reports of spirometric indices were associated with the period of publication, provision of lung function reference values and information on spirometry quality control. Not surprisingly, newer studies reported higher lung function values.

The main strength of this study is in its methodology. We performed the search without language restrictions and screened the full text of every identified clinical study with an original study population, even if lung function was not explicitly mentioned in the abstract. This ensured that we included studies 


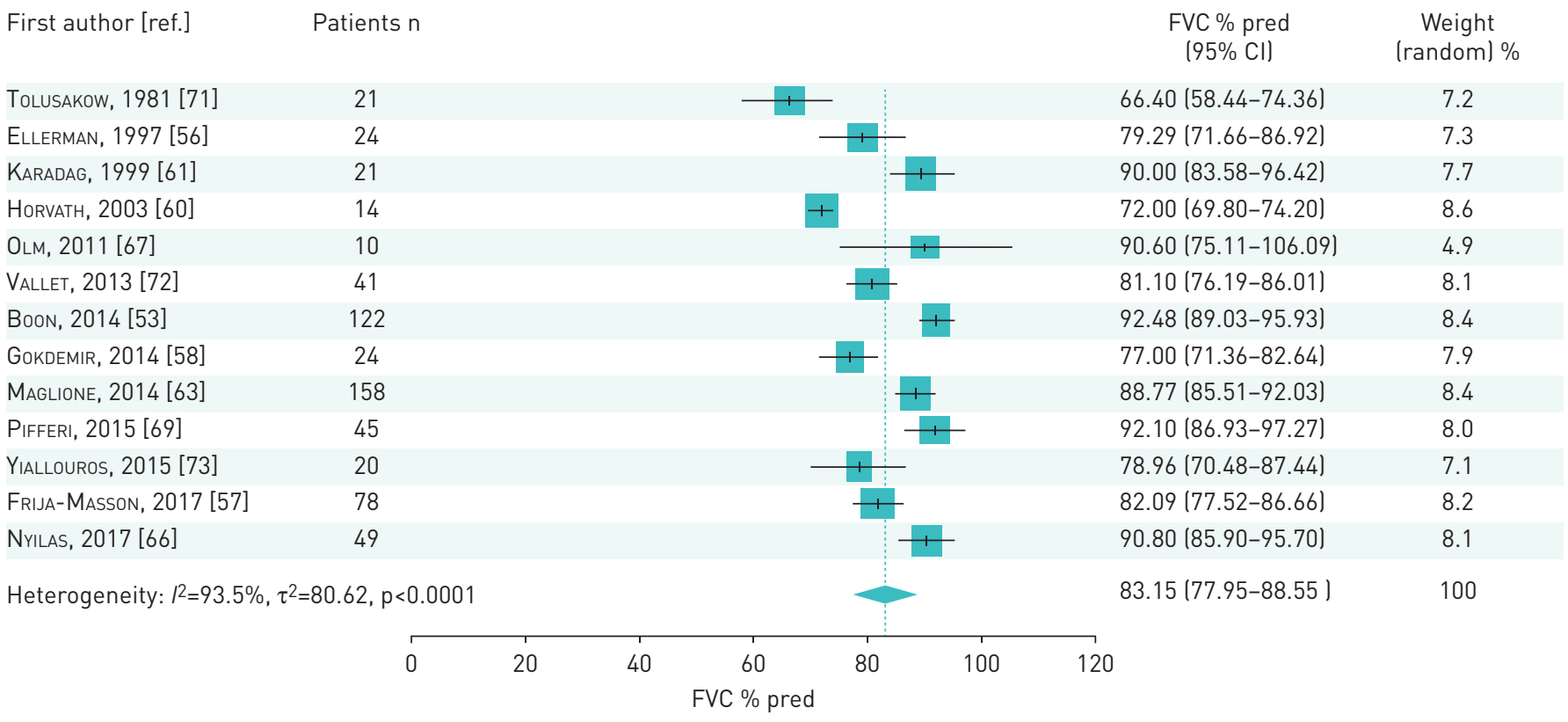

FIGURE 4 Forced vital capacity (FVC) in primary ciliary dyskinesia patients: forest plot showing the heterogeneity and weighted mean value of FVC $\%$ pred in the included studies.

that a custom approach might miss. We contacted primary investigators of the included studies to acquire spirometric indices in a consistent form in order to pool them in meta-analyses, and we separated our results for paediatric and adult patients. We also accounted for heterogeneity in the results by performing a meta-regression with all available explanatory factors. However, we were not able to include other factors that were possibly known but not published in the studies. These include genetic variations in studied populations, which are known to result in varying disease severity [52, 55], other indicators of disease severity such as imaging data to assess structural changes in the lungs, and less well-documented clinical factors such as compliance, adherence to therapy, age at diagnosis, and varying standards in clinical surveillance and treatment (e.g. history of lobectomy and clinical status at the time of measurement).

We restricted our search to studies published since 1980 for several reasons. Many things have changed in understanding and characterising PCD since it was first described by Kartagener in the early 1930s. Older studies are often not available online or do not have an abstract in the online databases. In addition, clinical studies of PCD before 1980 were mostly case reports or small studies with less than 10 patients that were not eligible for our review.

Our review undoubtedly reflects the weaknesses of its included studies, most of which suffered from significant selection bias. Its important limitations involve the differences in study designs and aims of the included studies that might have directly influenced the lung function assessment of study populations. Most studies used a convenience patient sample and did not describe how the participants were selected. It is possible that in some cases patients with more severe respiratory problems were recruited whose lung function might be more impaired. We did not perform a risk of bias assessment for the studies included in this review. We expected all studies to suffer from moderate to serious risk, which is common in these types of studies, especially in rare diseases, e.g. small studies mainly based on case series of patients. Our most important limitation is that we could not compare the spirometric indices of the included studies using the same reference values and, ideally, use z-scores for FEV1 and FVC. Unfortunately, the majority of included studies reported percent predicted values derived from a variety of references. To address this issue, we tested the particular lung function reference as a possible explanatory factor in the heterogeneity in our meta-regression.

We do not expect significant diagnostic misclassification in the included studies, mainly because most studies adhered to consensus guidelines and were published more recently [74]. However, misclassification bias is still possible, especially for the older studies. When we repeated our meta-analyses excluding the two studies with only clinical diagnoses the results did not change. As most studies suffered from the same design flaws, we did not apply any quality assessment criteria to decide which studies to include in our meta-analysis.

Due to the considerable heterogeneity, the calculated mean weighted values of percent predicted FEV1 and FVC should be interpreted with caution. The meta-analysis was performed to quantify the variability in 
reported spirometric indices and not to give valid estimates. The possible explanatory factors we tested failed to explain this heterogeneity. Still, some factors contributed to explaining differences in FEV 1 and FVC in the included studies. Publication year may be indicative of differences in awareness and disease diagnosis as well as changes in standardisation of treatment and routine surveillance of patients. Recent studies are more likely to have used modern diagnostic approaches, and include more patients who are correctly diagnosed and patients who have less severe disease and more genetic variations compared with older studies. They also usually include patients treated with more modern treatment protocols, and use newer and more correct spirometry reference values. Studies that did not report information on quality control of spirometry data or lung function reference values might have had less strict protocols for lung function measurements compared with studies that reported this information in detail. Although it was not possible to pool the studies including repeated lung function measurements and study disease progression over time, the reported percent predicted FEV1 was lower in adult patients compared with children. On the one hand, this could support the progression of lung disease into adulthood; on the other hand, differences between adults and children might also reflect differences in disease management or diagnosis over the years.

Methodological variability in the studies we included could not explain the heterogeneity in lung function. We believe that this heterogeneity is caused by factors that could not be tested in a meta-analysis given the information that we had available (e.g. genetic factors, differences in disease management, factors related to the variability of study inclusion criteria, and details on the performance and evaluation of lung function measurements). This heterogeneity in lung function measurements goes hand in hand with the heterogeneity we reported in our previous review on the clinical manifestations of PCD, which highlights the limitations of published studies to describe the full clinical spectrum of PCD [3]. However, the results of both reviews underline the possibility of distinctly different disease phenotypes, which also are observed in other chronic respiratory diseases [75-77]. This is further supported by reports that link specific ultrastructural defects and genetic mutations with more severe lung disease. In a study of North American children with PCD, those with an absence of inner dynein arms in conjunction with central apparatus defects and microtubular disorganisation associated with CCDC39 and CCDC40 mutations had lower spirometric indices compared with other PCD patients [55]. Data from a smaller case series of Israeli patients, analysed together with data from previous case reports, found that patients with CCNO mutations showed rapid deterioration of lung function $[52,78,79]$.

All these findings demonstrate the need for collaborative, prospective studies that use standardised protocols for spirometry and international up-to-date reference values. To meet this need, together with a network of international collaborators we are developing a standardised, disease-specific instrument for patient follow-up and prospective data collection [80,81]. At the same time, researchers in centres around the world are conducting a prospective multicentre observational study of variability of lung function in PCD patients (PROVALF-PCD) that will provide information on how FEV1 itself varies in individual stable PCD patients [82]

\section{Conclusions}

Spirometric indices of PCD patients vary significantly between published studies, which not only suggests the possibility of methodological differences between centres, but also real differences in disease expression. Detailed characterisation of different PCD phenotypes in studies that use standardised outcome measures and protocols, international up-to-date reference values, and, ideally, phenotype-genotype associations are needed to explain this variability and to better understand the natural history of PCD.

Acknowledgements: We thank Christopher Ritter (Institute of Social and Preventive Medicine, University of Bern, Bern, Switzerland) for his editorial suggestions.

Author contributions: M. Goutaki and C.E. Kuehni developed the concept and designed the study. M. Goutaki and A. Jose performed the systematic search, selected the included studies and extracted the data. F.S. Halbeisen and M. Goutaki analysed the data and drafted the initial manuscript. All authors contributed to iterations and approved the final version. M. Goutaki, C.E. Kuehni and F.S. Halbeisen take final responsibility for the contents.

Conflict of interest: F.S. Halbeisen has nothing to disclose. A. Jose has nothing to disclose. C. de Jong has nothing to disclose. S. Nyilas has nothing to disclose. P. Latzin reports personal fees from Gilead, Novartis, Polyphor, Roche, Santhera, Schwabe, Vertex, Vifor and Zambon, all outside the submitted work. C.E. Kuehni has nothing to disclose. M. Goutaki has nothing to disclose.

Support statement: This study was supported by the Swiss National Foundation (SNF 320030_173044) and the Milena-Carvajal Pro Kartagener Foundation. The researchers participate in the network of COST Action BEAT-PCD: Better Experimental Approaches to Treat PCD (BM1407). Funding information for this article has been deposited with the Crossref Funder Registry. 


\section{References}

1 Lucas JS, Walker WT, Kuehni CE, et al. Primary ciliary dyskinesia. In: Courdier J-F, ed. Orphan Lung Diseases (ERS Monograph). Sheffield, European Respiratory Society, 2011; pp. 201-217.

2 Kuehni CE, Frischer T, Strippoli MP, et al. Factors influencing age at diagnosis of primary ciliary dyskinesia in European children. Eur Respir J 2010; 36: 1248-1258.

3 Goutaki M, Meier AB, Halbeisen FS, et al. Clinical manifestations in primary ciliary dyskinesia: systematic review and meta-analysis. Eur Respir J 2016; 48: 1081-1095.

4 Noone PG, Leigh MW, Sannuti A, et al. Primary ciliary dyskinesia: diagnostic and phenotypic features. Am J Respir Crit Care Med 2004; 169: 459-467.

5 Miller MR, Pedersen OF, Lange P, et al. Improved survival prediction from lung function data in a large population sample. Respir Med 2009; 103: 442-448.

6 Bailey KL. The importance of the assessment of pulmonary function in COPD. Med Clin North Am 2012; 96 745-752.

7 Davies JC, Alton EW. Monitoring respiratory disease severity in cystic fibrosis. Respir Care 2009; 54: 606-617.

8 Rabe KF, Hurd S, Anzueto A, et al. Global strategy for the diagnosis, management, and prevention of chronic obstructive pulmonary disease: GOLD executive summary. Am J Respir Crit Care Med 2007; 176: 532-555.

9 Pinkerton KE, Harbaugh M, Han MK, et al. Women and lung disease. Sex differences and global health disparities. Am J Respir Crit Care Med 2015; 192: 11-16.

10 Moher D, Liberati A, Tetzlaff J, et al. Preferred reporting items for systematic reviews and meta-analyses: the PRISMA statement. PLoS Med 2009; 6: e1000097.

11 Lucas JS, Barbato A, Collins SA, et al. European Respiratory Society guidelines for the diagnosis of primary ciliary dyskinesia. Eur Respir J 2017; 49: 1601090.

12 Lucas JS, Paff T, Goggin P, et al. Diagnostic methods in primary ciliary dyskinesia. Paediatr Respir Rev 2016; 18 : 8-17.

13 DerSimonian R, Laird N. Meta-analysis in clinical trials. Control Clin Trials 1986; 7: 177-188

14 Higgins JP, Thompson SG, Spiegelhalter DJ. A re-evaluation of random-effects meta-analysis. J R Stat Soc Ser A Stat Soc 2009; 172: 137-159.

15 Higgins JP, Thompson SG. Quantifying heterogeneity in a meta-analysis. Stat Med 2002; 21: 1539-1558.

16 Quanjer PH, Weiner DJ. Interpretative consequences of adopting the Global Lungs 2012 reference equations for spirometry for children and adolescents. Pediatr Pulmonol 2014; 49: 118-125.

17 Miller MR, Hankinson J, Brusasco V, et al. Standardisation of spirometry. Eur Respir J 2005; 26: 319-338.

18 Alanin MC, Aanaes K, Hoiby N, et al. Sinus surgery can improve quality of life, lung infections, and lung function in patients with primary ciliary dyskinesia. Int Forum Allergy Rhinol 2017; 7: 240-247.

19 Boon M, De Boeck K, Jorissen M, et al. Primary ciliary dyskinesia and humoral immunodeficiency - is there a missing link? Respir Med 2014; 108: 931-934.

20 Boon M, Vermeulen FL, Gysemans W, et al. Lung structure-function correlation in patients with primary ciliary dyskinesia. Thorax 2015; 70: 339-345.

21 Green K, Buchvald FF, Marthin JK, et al. Ventilation inhomogeneity in children with primary ciliary dyskinesia. Thorax 2012; 67: 49-53.

22 Green K, Ejlertsen JS, Madsen A, et al. Abbreviation modalities of nitrogen multiple-breath washout tests in school children with obstructed lung disease. Pediatr Pulmonol 2016; 51: 624-632.

23 Groth S, Pedersen M. Pulmonary permeability in primary ciliary dyskinesia. Eur Respir J 1989; 2: 64-70.

24 Madsen A, Green K, Buchvald F, et al. Aerobic fitness in children and young adults with primary ciliary dyskinesia. PLoS One 2013; 8: e71409.

25 Marthin JK, Petersen N, Skovgaard LT, et al. Lung function in patients with primary ciliary dyskinesia: a cross-sectional and 3-decade longitudinal study. Am J Respir Crit Care Med 2010; 181: 1262-1268.

26 Maglione M, Bush A, Montella S, et al. Progression of lung disease in primary ciliary dyskinesia: is spirometry less accurate than CT? Pediatr Pulmonol 2012; 47: 498-504.

27 Magnin ML, Cros P, Beydon N, et al. Longitudinal lung function and structural changes in children with primary ciliary dyskinesia. Pediatr Pulmonol 2012; 47: 816-825.

28 Montella S, Santamaria F, Salvatore M, et al. Lung disease assessment in primary ciliary dyskinesia: a comparison between chest high-field magnetic resonance imaging and high-resolution computed tomography findings. Ital J Pediatr 2009; 35: 24

29 Pifferi M, Bush A, Pioggia G, et al. Evaluation of pulmonary disease using static lung volumes in primary ciliary dyskinesia. Thorax 2012; 67: 993-999.

30 Santamaria F, De Stefano S, Montella S, et al. Nasal nitric oxide assessment in primary ciliary dyskinesia using aspiration, exhalation, and humming. Med Sci Monit 2008; 14: CR80-CR85.

31 Santamaria F, Montella S, Tiddens H, et al. Structural and functional lung disease in primary ciliary dyskinesia. Chest 2008; 134: 351-357.

32 Valerio G, Giallauria F, Montella S, et al. Cardiopulmonary assessment in primary ciliary dyskinesia. Eur J Clin Invest 2012; 42: 617-622.

33 Loomba RS, Danduran M, Nielsen KG, et al. Cardiopulmonary exercise testing in Fontan patients with and without isomerism (heterotaxy) as compared to patients with primary ciliary dyskinesia and subjects with structurally normal hearts. Pediatr Cardiol 2017; 38: 410-417.

34 Noone PG, Bennett WD, Regnis JA, et al. Effect of aerosolized uridine-5'-triphosphate on airway clearance with cough in patients with primary ciliary dyskinesia. Am J Respir Crit Care Med 1999; 160: 144-149.

35 Radhakrishnan DK, Bendiak GN, Mateos-Corral D, et al. Lower airway nitric oxide is increased in children with sickle cell disease. J Pediatr 2012; 160: 93-97.

36 Ratjen F, Waters V, Klingel M, et al. Changes in airway inflammation during pulmonary exacerbations in patients with cystic fibrosis and primary ciliary dyskinesia. Eur Respir J 2016; 47: 829-836.

37 Regnis JA, Zeman KL, Noone PG, et al. Prolonged airway retention of insoluble particles in cystic fibrosis versus primary ciliary dyskinesia. Exp Lung Res 2000; 26: 149-162.

38 Nyilas S, Schlegtendal A, Yammine S, et al. Further evidence for an association between LCI and FEV1 in patients with PCD. Thorax 2015; 70: 896. 
39 Nyilas S, Singer F, Kumar N, et al. Physiological phenotyping of pediatric chronic obstructive airway diseases. J Appl Physiol 2016; 121: 324-332.

40 Werner C, Lablans M, Ataian M, et al. An international registry for primary ciliary dyskinesia. Eur Respir J 2016; 47: 849-859.

41 Bush A, Payne D, Pike S, et al. Mucus properties in children with primary ciliary dyskinesia: comparison with cystic fibrosis. Chest 2006; 129: 118-123.

42 Csoma Z, Bush A, Wilson NM, et al. Nitric oxide metabolites are not reduced in exhaled breath condensate of patients with primary ciliary dyskinesia. Chest 2003; 124: 633-638.

43 Irving SJ, Ives A, Davies G, et al. Lung clearance index and high-resolution computed tomography scores in primary ciliary dyskinesia. Am J Respir Crit Care Med 2013; 188: 545-549.

44 Narang I, Ersu R, Wilson NM, et al. Nitric oxide in chronic airway inflammation in children: diagnostic use and pathophysiological significance. Thorax 2002; 57: 586-589.

45 Paraskakis E, Zihlif N, Bush A. Nitric oxide production in PCD: possible evidence for differential nitric oxide synthase function. Pediatr Pulmonol 2007; 42: 876-880.

46 Phillips GE, Thomas S, Heather S, et al. Airway response of children with primary ciliary dyskinesia to exercise and $\beta_{2}$-agonist challenge. Eur Respir J 1998; 11: 1389-1391.

47 Shoemark A, Wilson R. Bronchial and peripheral airway nitric oxide in primary ciliary dyskinesia and bronchiectasis. Respir Med 2009; 103: 700-706.

48 Sunther M, Bush A, Hogg C, et al. Recovery of baseline lung function after pulmonary exacerbation in children with primary ciliary dyskinesia. Pediatr Pulmonol 2016; 51: 1362-1366.

49 Zihlif N, Paraskakis E, Lex C, et al. Correlation between cough frequency and airway inflammation in children with primary ciliary dyskinesia. Pediatr Pulmonol 2005; 39: 551-557.

50 Zihlif N, Paraskakis E, Tripoli C, et al. Markers of airway inflammation in primary ciliary dyskinesia studied using exhaled breath condensate. Pediatr Pulmonol 2006; 41: 509-514.

51 Al Saadi MM, Habib SS, Al Muqhem BA, et al. Significance of fractional exhaled nitric oxide measurements in detecting primary ciliary dyskinesia in Saudi children. Saudi Med J 2013; 34: 24-28.

52 Amirav I, Wallmeier J, Loges NT, et al. Systematic analysis of CCNO variants in a defined population: implications for clinical phenotype and differential diagnosis. Hum Mutat 2016; 37: 396-405.

53 Boon M, Smits A, Cuppens H, et al. Primary ciliary dyskinesia: critical evaluation of clinical symptoms and diagnosis in patients with normal and abnormal ultrastructure. Orphanet J Rare Dis 2014; 9: 11.

54 Cohen-Cymberknoh M, Simanovsky N, Hiller N, et al. Differences in disease expression between primary ciliary dyskinesia and cystic fibrosis with and without pancreatic insufficiency. Chest 2014; 145: 738-744.

55 Davis SD, Ferkol TW, Rosenfeld M, et al. Clinical features of childhood primary ciliary dyskinesia by genotype and ultrastructural phenotype. Am J Respir Crit Care Med 2015; 191: 316-324.

56 Ellerman A, Bisgaard H. Longitudinal study of lung function in a cohort of primary ciliary dyskinesia. Eur Respir J 1997; 10: 2376-2379.

57 Frija-Masson J, Bassinet L, Honore I, et al. Clinical characteristics, functional respiratory decline and follow-up in adult patients with primary ciliary dyskinesia. Thorax 2017; 72: 154-160.

58 Gokdemir Y, Karadag-Saygi E, Erdem E, et al. Comparison of conventional pulmonary rehabilitation and high-frequency chest wall oscillation in primary ciliary dyskinesia. Pediatr Pulmonol 2014; 49: 611-616.

59 Hellinckx J, Demedts M, De Boeck K. Primary ciliary dyskinesia: evolution of pulmonary function. Eur J Pediatr 1998; 157: 422-426.

60 Horvath I, Loukides S, Wodehouse $\mathrm{T}$, et al. Comparison of exhaled and nasal nitric oxide and exhaled carbon monoxide levels in bronchiectatic patients with and without primary ciliary dyskinesia. Thorax 2003; 58 $68-72$.

61 Karadag B, James AJ, Gultekin E, et al. Nasal and lower airway level of nitric oxide in children with primary ciliary dyskinesia. Eur Respir J 1999; 13: 1402-1405.

62 Koh YY, Park Y, Jeong JH, et al. The effect of regular salbutamol on lung function and bronchial responsiveness in patients with primary ciliary dyskinesia. Chest 2000; 117: 427-433.

63 Maglione M, Bush A, Nielsen KG, et al. Multicenter analysis of body mass index, lung function, and sputum microbiology in primary ciliary dyskinesia. Pediatr Pulmonol 2014; 49: 1243-1250.

64 Mahut B, Escudier E, de Blic J, et al. Impairment of nitric oxide output of conducting airways in primary ciliary dyskinesia. Pediatr Pulmonol 2006; 41: 158-163.

65 Mossberg B, Camner P, Afzelius BA. The immotile-cilia syndrome compared to other obstructive lung diseases: a clue to their pathogenesis. Eur J Respir Dis Suppl 1983; 127: 129-136.

66 Nyilas S, Schlegtendal A, Singer F, et al. Alternative inert gas washout outcomes in patients with primary ciliary dyskinesia. Eur Respir J 2017; 49: 1600466.

67 Olm MA, Kogler JE Jr, Macchione M, et al. Primary ciliary dyskinesia: evaluation using cilia beat frequency assessment via spectral analysis of digital microscopy images. J Appl Physiol 2011; 111: 295-302.

68 Paff T, van der Schee MP, Daniels JM, et al. Exhaled molecular profiles in the assessment of cystic fibrosis and primary ciliary dyskinesia. J Cyst Fibros 2013; 12: 454-460.

69 Pifferi M, Bush A, Michelucci A, et al. Mannose-binding lectin 2 gene polymorphism and lung damage in primary ciliary dyskinesia. Pediatr Pulmonol 2015; 50: 179-186.

70 Shah A, Shoemark A, MacNeill SJ, et al. A longitudinal study characterising a large adult primary ciliary dyskinesia population. Eur Respir J 2016; 48: 441-450.

71 Tolusakow WL, Boikow GA, Lewaschow JN, et al. Bronchiektasen bei Kranken mit Situs inversus viscerum (Kartagener Syndrom) [Bronchiectasis in patients with situs in versus viscerum (Kartagener syndrome) (author's transl)]. Z Erkr Atmungsorgane 1981; 156: 167-175.

72 Vallet C, Escudier E, Roudot-Thoraval F, et al. Primary ciliary dyskinesia presentation in 60 children according to ciliary ultrastructure. Eur J Pediatr 2013; 172: 1053-1060

73 Yiallouros PK, Kouis P, Middleton N, et al. Clinical features of primary ciliary dyskinesia in Cyprus with emphasis on lobectomized patients. Respir Med 2015; 109: 347-356.

74 Barbato A, Frischer T, Kuehni CE, et al. Primary ciliary dyskinesia: a consensus statement on diagnostic and treatment approaches in children. Eur Respir J 2009; 34: 1264-1276. 
75 Pembrey L, Barreto ML, Douwes J, et al. Understanding asthma phenotypes: the World Asthma Phenotypes (WASP) international collaboration. ERJ Open Res 2018; 4: 00013-02018.

76 Davies JC, Griesenbach U, Alton E. Modifier genes in cystic fibrosis. Pediatr Pulmonol 2005; 39: 383-391.

77 Castellani C, Assael BM. Cystic fibrosis: a clinical view. Cell Mol Life Sci 2017; 74: 129-140.

78 Boon $\mathrm{M}$, Wallmeier J, Ma L, et al. MCIDAS mutations result in a mucociliary clearance disorder with reduced generation of multiple motile cilia. Nat Commun 2014; 5: 4418.

79 Wallmeier J, Al-Mutairi DA, Chen CT, et al. Mutations in CCNO result in congenital mucociliary clearance disorder with reduced generation of multiple motile cilia. Nat Genet 2014; 46: 646-651.

80 Rubbo B, Behan L, Dehlink E, et al. Proceedings of the COST action BM1407 inaugural conference BEAT-PCD: translational research in primary ciliary dyskinesia - bench, bedside, and population perspectives. BMC Proc 2016; 10: 66 .

81 Goutaki M, Halbeisen F, Hogg C, et al. Towards standardized follow-up care for patients with Primary Ciliary Dyskinesia (PCD). Eur Respir J 2017; 50: Suppl. 61, PA1847.

82 Halbeisen F, Hogg C, Alanin MC, et al. Proceedings of the 2nd BEAT-PCD conference and 3rd PCD training school: part 1. BMC Proc 2018; 12: 1. 